\title{
Spinal and supraspinal adaptations associated with balance training and their functional relevance
}

\author{
W. Taube, M. Gruber and A. Gollhofer \\ Department of Sport Science, University of Freiburg, Freiburg, Germany
}

Correspondence: W. Taube. Department of Sport Science, University of Freiburg, Schwarzwaldstr. 175, 79117 Freiburg i.Br. Germany.

E-mail: wolfgang.taube@sport.unifreiburg.de

\begin{abstract}
Traditionally, balance training has been used to rehabilitate ankle injuries and postural deficits. Prospective studies have shown preventive effects with respect to ankle and knee joint injuries. Presently, balance training is not only applied for rehabilitation and prevention but also for improving motor performance, especially muscle power. The recent application of noninvasive electrophysiological and brain imaging techniques revealed insights into the central control of posture and the adaptations induced by balance training. This information is important for our understanding of the basic control and adaptation mechanisms and to conceptualize appropriate training programmes for athletes, elderly people and patients. The present review presents neurophysiological adaptations induced by balance training and their influence on motor behaviour. It emphasizes the plasticity of the sensorimotor system, particularly the spinal and supraspinal structures. The relevance of balance training is highlighted with respect to athletic performance, postural control within elderly people as well as injury prevention and rehabilitation.
\end{abstract}

Keywords plasticity, posture, sensorimotor training.
In contrast to all other mammals, humans sustain bipedal stance and gait as their normal posture and locomotion. As a consequence, humans are required to balance multiple segments with a high centre of mass over a small base of support. It takes children 7 years or more to acquire adult-like balance-control strategies. This means that everyone experiences some kind of 'balance' or 'postural' training as part of the normal development during childhood. Although the greatest improvements take place during childhood, the ability to adapt postural control is preserved in adults and elderly people. In particular, exposure to unstable support surfaces proved beneficial in training postural control. Unfortunately, there is no consistent term to summarize balance exercises that aim at improving postural stability. Some authors refer to it as 'balance training' (Bernier \& Perrin 1998, Heitkamp et al. 2001), while others call it 'sensorimotor training' (Banaschewski et al. 2001, Gruber \& Gollhofer 2004) 'neuromuscular training' (Paterno et al. 2004) or 'proprioceptive training' (Wulker \& Rudert 1999, Chong et al. 2001). The expression proprioceptive training is incorrectly limited to the perception of afferent input and does not take into account adaptations occurring on the motor side (for a review, see Ashton-Miller et al. 2001). Neuromuscular and sensorimotor training are so wide-ranging, that multiple kinds of exercise can be described in terms of a neuromuscular or sensorimotor task. Balance training seems most appropriate as it refers to balance exercises with the primary intention of improving balance. This means that the term 'balance training' does not comprise specific biological structures, which may adapt in response to the training intervention, but rather describes the progress in performing a particular skill. Potentially, balance training induces adaptations in all the sensory systems assisting postural control, such as the vestibular, the visual, and the somatosensory system as well as in the motor systems controlling muscular output. 
The exercises and tasks incorporated into balance training can greatly vary. This review focuses on balance interventions in which subjects performed one or two legged exercises on unstable support surfaces. In most of the studies presented, subjects exercised on a selection of different training devices (e.g. wobbling boards, tilt boards, spinning tops, half discs, soft mats, cushions, etc.). So far, there are no scientific guidelines concerning the optimal duration and intensity of these exercises and thus, there is large variation in these parameters between studies. Figure 1 illustrates an example of a balance training procedure that has been used in a number of recent studies (Eils \& Rosenbaum 2001, Bruhn et al. 2004, 2006, Gruber \& Gollhofer 2004, Granacher et al. 2006, Beck et al. 2007, Gruber et al. 2007a,b, Taube et al. 2007a,b, Schubert et al. 2008).

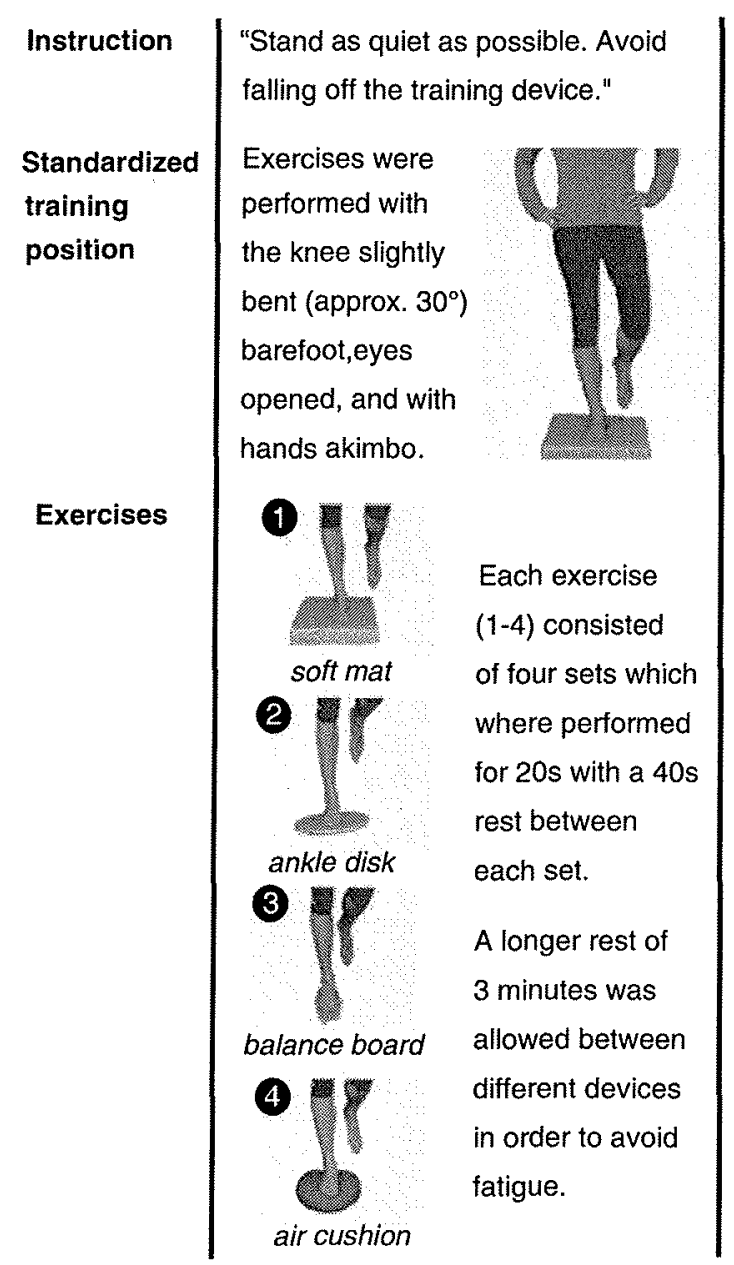

Figure I An example of a balance training programme. Exercises are performed in one-legged stance on different training devices. The total duration of each training session is $60 \mathrm{~min}$, including a 10 -min warm-up and a $10-\mathrm{min}$ cool-down (modified from Gruber et al. 2007a).
Contrary to many other training interventions, balance training can be performed by athletes, children, elderly people and disabled people. Thus, balance training is a beneficial tool that induces adaptations in multiple target groups. The review begins with a brief account of these functional adaptations, i.e. how motor performance is affected by balance training and what consequences this might have for injury prevention and rehabilitation. The main section describes the underlying neural adaptations of balance training and differentiates between spinal and supraspinal adaptations.

\section{Functional adaptations associated with balance training}

\section{Motor performance}

Freeman et al. (1965) scientifically showed that balance training had a positive effect upon the ability to control upright posture in persons with ligamentous injuries of the foot and ankle. Long before that Tai Chi was (and still is) considered to establish inner (mental) and outer balance and was invented in China as early as in the 14th century. In Europe, artists demonstrated highly developed balance skills on tightropes some hundred years ago. In recent years, scientific studies confirmed that postural control is highly adaptable and can be improved through balance training in children, adults, elderly people as well as in patients and elite athletes (Heitkamp et al. 2001, Granacher et al. 2006, Myer et al. 2006, Yaggie \& Campbell 2006, Beck et al. 2007, Gruber et al. 2007a, Taube et al. 2007a). As postural control constitutes a limiting factor for many daily activities and a variety of physical exercises, training of postural control can directly influence performance in those activities.

The benefit of balance training is however not confined to the execution of postural tasks. Recent studies demonstrated that balance exercises also improved strength and jumping abilities (Heitkamp et al. 2001, Bruhn et al. 2004, Gruber \& Gollhofer 2004, Granacher et al. 2006, Kean et al. 2006, Myer et al. 2006, Gruber et al. 2007b, Taube et al. 2007b). Balance training influenced most efficiently the maximum rate of force development (Gruber \& Gollhofer 2004, Bruhn et al. 2006, Granacher et al. 2006, Gruber et al. 2007a). In untrained or impaired subjects balance training also enhanced maximal voluntary strength (Heitkamp et al. 2001, Hirsch et al. 2003, Bruhn et al. 2006). Highly relevant from a functional point of view is the observation that balance training was capable of improving vertical jump performance (Kean et al. 2006, Taube et al. 2007b). As balance training stresses the tendomuscular system marginally, these training effects might be particularly beneficial for pubertal children 
and athletes who face a risk of overload or overuse injuries.

\section{Injury prevention and rehabilitation}

Balance training can be implemented as a prophylactic intervention for daily activities and in sports disciplines in which loss of postural control is a risk factor. The preventive aspect of balance training was shown in a variety of prospective studies investigating team sports such as handball (Wedderkopp et al. 1999, 2003, Myklebust et al. 2003, 2007, Petersen et al. 2005), soccer (Caraffa et al. 1996, McGuine \& Keene 2006), basketball (McGuine \& Keene 2006, Emery et al. 2007) and volleyball (Bahr \& Bahr 1997, Verhagen et al. 2004).

Balance training can also prevent injuries in elderly people. Age-related impairments in postural control, which are accompanied by an enhanced risk of falling (Campbell et al. 1989, Lord et al. 1991), have been ascribed to deteriorations in both the sensory and motor systems (for a review, see Shaffer \& Harrison 2007). For example, advancing age has been associated with muscle weakness (Faulkner et al. 1990, Wolfson et al. 1995), reduced cutaneous sensation (Whanger $\&$ Wang 1974), decreased nerve conduction velocity (Dorfman \& Bosley 1979), diminished proprioception (Skinner et al. 1984) and reduction in efficient cortico motor neurones (Eisen et al. 1996). Training programmes can counteract these risk factors and restore balance control in elderly people (Rogers et al. 2003, Granacher et al. 2006). Although many of these studies indicated improved postural control after training, it is not possible to ascribe these effects to balance training alone as most studies incorporated a combination of balance and strength training as well as medical treatment (Liu-Ambrose et al. 2004, Nelson et al. 2004). Similarly, prospective studies did not solely focus on the effect of balance training (Close et al. 1999, Robertson et al. 2002). The positive treatment effect (e.g. fall reduction) cannot therefore be exclusively attributed to balance exercises.

Apart from its injury prevention potential, balance training improves the regeneration of neuromuscular structures following injury (Freeman et al. 1965, Gauffin et al. 1988, Rozzi et al. 1999, Eils \& Rosenbaum 2001, Henriksson et al. 2001) and efficiently prevents injury re-occurrence (Holme et al. 1999, Verhagen et al. 2004, McGuine \& Keene 2006). In stroke patients and in people with vestibular dysfunction, postural stability was improved after participating in rehabilitation programmes that incorporated balance exercises (Herdman et al. 1995, de Haart et al. 2004, Rine et al. 2004, Yavuzer et al. 2006).

\section{Neural adaptations associated with balance training}

The localization and neural mechanisms underlying the functional adaptations cited in the preceding text were determined using electrophysiological and imaging techniques. Recent studies demonstrated that these adaptations are located at different sites of the central nervous system.

\section{Spinal adaptations}

The spinal reflex system is considered to play an important role in the control of quiet unperturbed stance (Bove et al. 2006, Tokuno et al. 2007) as well as during the compensatory reaction following postural disturbances (Dietz et al. 1988). Below, we first introduce techniques for evaluating the spinal contribution during balance tasks and then provide evidence for the adaptability of spinal structures in response to changes in postural demand and postural training.

Techniques for measuring spinal adaptations. To evaluate adaptive plasticity at the spinal level, the Hoffmann- $(\mathrm{H}-)$ reflex has been extensively employed (for a review, see Schieppati 1987, Zehr 2002). Electrical stimulation of the tibial nerve in the popliteal fossa evokes an $\mathrm{H}$-reflex of the soleus muscle. As the tibial nerve contains both sensory and motor axons, electrical stimulation of this nerve elicits a reflexive response (H-reflex with a latency of $\sim 35 \mathrm{~ms}$ ) and a direct muscle response (M-wave with a latency of $\sim 10 \mathrm{~ms}$ ). The H-reflex is mediated via action potentials from the Ia-afferents to the $\alpha$-motor neurone and finally, to the neuromuscular junction. The $\mathrm{M}$-wave travels from the point of stimulation directly via motor axons to the neuromuscular junction. Low stimulation intensity results in a small $\mathrm{H}$-reflex without any $\mathrm{M}$-wave because the larger diameter la-afferents are recruited before the smaller motor axons. When the stimulation intensity is successively increased from low levels sufficient to elicit a small $\mathrm{H}$-reflex, up to $\mathrm{H}_{\max }$ and then $\mathrm{M}_{\max }$, an $\mathrm{H}$-reflex recruitment curve can be obtained (Schieppati 1987, see also Fig. 2A). Expressing the maximal $\mathrm{H}$-reflex relative to $M_{\max }\left(H_{\max } / M_{\max }\right.$-ratio) counteracts the potential problem of ensuring identical EMG recording conditions in pre- and post-training measurements (Aagaard et al. 2002). As long as the peripheral inputs, i.e. same posture and comparable activation of other muscles, are kept constant, changes in the $\mathrm{H}_{\max } / \mathrm{M}_{\max }$-ratio following training indicate altered susceptibility of the $\alpha$-motor neurone pool in response to la-afferent signals (Zehr 2002). Enhanced $H_{\max } / M_{\max }$-ratios point towards enhanced motor neurone excitability and/or reduced presynaptic inhibition of la-afferent terminals 

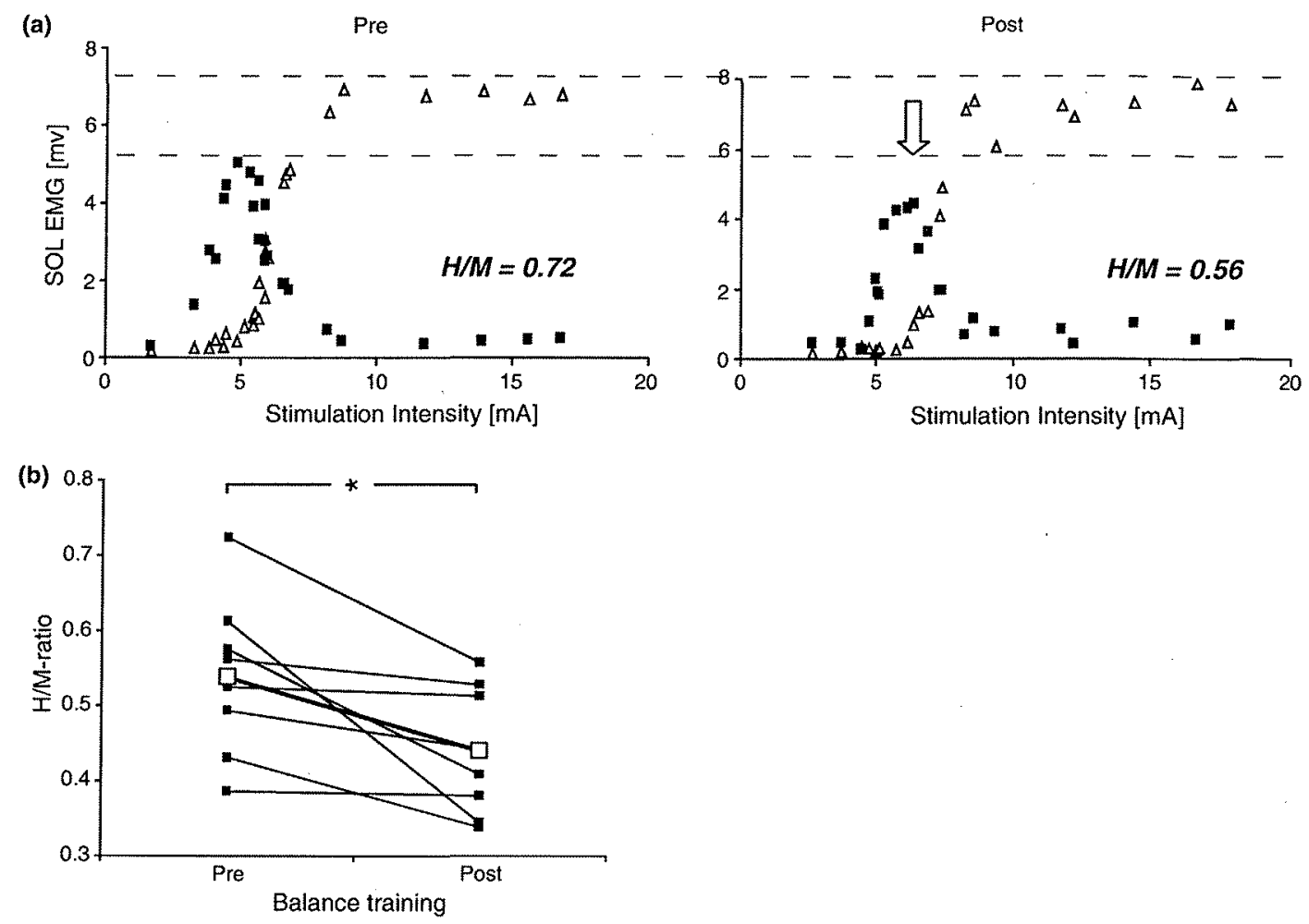

Figure 2 Adaptation of the H-reflex associated with 4 weeks of balance training (16 training sessions in total). H-reflex recruitment curves and resulting $\mathrm{H}_{\max } / \mathrm{M}_{\max }$-ratios were recorded during support surface perturbations. In (a) $\mathrm{H}$-reflex recruitment curves ( $\mathrm{H}$-reflexes, $\triangle \mathrm{M}$-waves) from one subject before (pre) and after balance training (post) illustrate the reduction in $H_{\max } / M_{\max }$-ratio $(\Omega)$. (b) $H_{\max } / M_{\max }$-ratios from each single subject $(\square)$ as well as the mean of all subjects $(\square)$ are displayed $\left(P<0.05^{*}\right)$ (modified from Taube et al. 2007b.)

(Aagaard et al. 2002). Both mechanisms increase $\alpha$-motor neurone output and consequently, the neural drive to the muscle. This may be beneficial for generating high muscular forces (Aagaard et al. 2002, Lagerquist et al. 2006, Taube et al. 2007b). On the contrary, reduced $\mathrm{H}_{\max } / \mathrm{M}_{\max }$-ratios after training indicate inhibition of the la afferent pathway resulting in less contribution from the muscle spindles in generating excitation to muscular activation. Functionally, this may prevent reflex-mediated (destabilizing) movements (Llewellyn et al. 1990) and consequently enhance movement control of supraspinal centres (Solopova et al. 2003).

Instantaneous reflex modulation. The human central nervous system responds instantaneously to changes in the support surface or alterations in the peripheral feedback. For example, balancing on a narrow beam reduces the $\mathrm{H}$-reflex amplitude compared to normal walking (Llewellyn et al. 1990). Similarly, H-reflexes are diminished during stance as soon as the eyes are closed (Hoffman \& Koceja 1995, Earles et al. 2000). Both examples indicate that the la afferent transmission is reduced in the more demanding task. Conversely, $\mathrm{H}$-reflexes are facilitated as soon as the postural demands are lowered, for instance with the help of additional mechanical support (Katz et al. 1988, Trimble 1998). These observations demonstrate that the human spinal reflex system is highly adaptable and responds rapidly to environmental changes (for a review, see Wolpaw \& Tennissen 2001). The functional significance of such a task and posture-specific reflex modulation might be deduced from people who cannot alter their reflex behaviour. Patients with cerebellar ataxia who were unable to suppress their $\mathrm{H}$-reflexes stood more unstable than healthy subjects (Tokuda et al. 1991). Similarly, unbalanced stance in patients with Parkinson's disease was accompanied by the inability to alter the H-reflex amplitude in a taskspecific manner (Hayashi et al. 1997). The advantage of reduced spinal reflexes in balancing tasks was assumed to rely on the prevention of reflex-mediated joint oscillations and on a shift in movement control to higher centres (Llewellyn et al. 1990, Koceja \& Mynark 2000, Solopova et al. 2003). The diminished spinal reflexes might therefore indicate both re-weighting of 
sensory information (Maurer et al. 2006) as well as altered contributions of motor centres (Solopova et al. 2003, Taube et al. 2007a).

Effects of short-and long-term training on spinal reflex circuits. Apart from the instantaneous reflex modulations resulting from changes in the postural task complexity, humans can learn to adjust their spinal reflexes in response to a specific standing condition. For instance, when subjects are exposed to an unstable support surface and the H-reflex is used as a destabilizing stimulus, subjects learn to suppress their H-reflexes within $2 \mathrm{~h}$ (Trimble \& Koceja 1994, 2001). This ability to down-train the H-reflex is preserved in elderly people ( $>65$ years) and is accompanied by an enhanced stance stability (Mynark \& Koceja 2002). One might speculate that the subjects simply reduced the H-reflex to minimize the disturbing stimulus. However, recent studies have demonstrated that training on unstable ground without the disturbing influence of the electrical nerve stimulation also induces a suppression of the H-reflex (Figure 2; Taube et al. 2007a, Gruber et al. 2007b, Taube et al. $2007 \mathrm{~b})$. In contrast to the relatively short training procedures presented by Trimble, Koceja and Mynark, balance training in the latter three studies (Gruber et al. 2007b, Taube et al. 2007a,b) proceeded 4 weeks or longer (16-18 training sessions). In one of these studies, a training induced H-reflex adaptation was measured at rest (Gruber et al. 2007b). This implies that balance training modifies spinal reflex circuits in general and leads to persistently reduced $\mathrm{H}$-reflexes in subjects who face high postural demands over a long time. The reduced $\mathrm{H}$-reflex excitability of ballet dancers might be explained in this way (Nielsen et al. 1993a). However, task specific reflex adaptations reported in other balance training studies suggest that the spinal reflex behaviour is primarily modified in the trained task.

Task-specific reflex adaptation. In a cross-sectional study, H-reflex gain was inhibited in well-trained dancers compared to physically active control subjects only when measurements took place during stance (postural task). No differences were observed in a prone position (Mynark \& Koceja 1997). Similarly, 6 weeks of balance training reduced $\mathrm{H}$-reflexes exclusively during a postural task on the treadmill but not during unperturbed stance (Taube et al. 2007b). In a recent study, evidence was provided that not only the task itself might be crucial for the training related $\mathrm{H}$-reflex modulation but also the phase of the movement (Taube et al. 2007a). After 4 weeks of balance training, subjects were tested while compensating for a rapid posterior displacement of the support surface.
$\mathrm{H}$-reflexes were elicited to coincide with either the peak of the short-latency response (SLR) occurring after approximately $50 \mathrm{~ms}$ or with the peak of the longlatency response (LLR) around $120 \mathrm{~ms}$. No adaptations were seen at the time of the spinally generated SLR whereas $\mathrm{H} / \mathrm{M}$-ratios were significantly reduced at the LLR.

Task-specific reflex adaptations were not only observed following balance training but also after strength and jumping training. Both interventions induced facilitation of spinal reflexes in the trained task, i.e. during isometric contractions and during hopping, respectively, but not at rest (Voigt et al. 1998, Aagaard et al. 2002). The task-specific reflex adaptations cited in the preceding text indicate that congruence of training and testing task is essential to assess training-related reflex adaptations.

Reflex adaptation in elderly people. In elderly people, changes in motor control strategy occur concurrently with constraints in the ability to modulate spinal reflex circuitries. In contrast to young adults, elderly subjects show less differentiated reflex modulations in response to changes in body posture (Koceja et al. 1995, Koceja \& Mynark 2000, Mynark \& Koceja 2002). It was assumed that an altered regulation of presynaptic inhibition onto Ia afferents contributed to the changes in the reflex characteristics (Koceja \& Mynark 2000, Tsuruike et al. 2003). However, this does not mean that elderly adults completely lose their ability to adjust reflex responses. During more demanding balance tasks like tandem stance, they showed similar depression of the H-reflex than young subjects (Chalmers \& Knutzen 2002). Furthermore, elderly subjects who underwent postural training were able to adapt their $\mathrm{H}$-reflexes by a similar amount as young subjects. After 2 days of exposure to 'spinally induced perturbations' (i.e. perturbations induced by electrical stimulation of the tibial nerve), elderly people reduced their $\mathrm{H}$-reflex amplitude by $21 \%$ and their area of sway by $10 \%$ (Mynark $\&$ Koceja 2002). Nevertheless, in contrast to young subjects, they did not modify reflex behaviour when switching from supine to upright stance positions. This might point towards an altered neural control strategy with ageing rather than a total inability to functionally adapt reflex responses. This assumption is supported by the study of Granacher et al. (2006) who reported alterations in the reflex behaviour of elderly people, which were accompanied by an improved stance and gait performance. The effects of 13 weeks of balance training were compared with the adaptations induced through strength training. Only the balance training group improved postural stability. Compared with the strength-trained group, balance-trained subjects demonstrated greater functional reflex responses in the 
prime movers, shorter onset latencies and smaller maximal angular velocities of the ankle joint while compensating perturbations during gait on a treadmill.

In conclusion, although the sensorimotor system of elderly people seems to be more restricted in modulating reflex responses, it is still capable of adapting in response to balance training. This might indicate that neural control of balance can be retrained and rehabilitated in subjects with impaired reflex function.

Neural mechanisms influencing reflex behaviour. Modulation of presynaptic inhibition onto la afferents was suggested to be the most likely mechanism of altering reflex behaviour in balance training studies (Trimble \& Koceja 1994, 2001, Gruber et al. 2007b, Taube et al. $2007 \mathrm{a}, \mathrm{b})$ and in studies investigating the relationship between reflex excitability and postural task complexity (Katz et al. 1988, Dietz et al. 1991, Mynark et al. 1997, Trimble 1998, Koceja \& Mynark 2000). In general, the level of presynaptic inhibition is believed to increase as the degree of postural instability increases (Capaday $\&$ Stein 1987, Katz et al. 1988).

The observation of an enhanced level of co-contraction during postural demanding tasks (Llewellyn et al. 1990, Nielsen \& Kagamihara 1992) might support such kind of reflex inhibition, as presynaptic inhibition of the soleus muscle was shown to increase during co-contraction (Nielsen \& Kagamihara 1993). One might argue that enhanced antagonistic activity might additionally alter reflex excitability by means of reciprocal inhibition. In this respect, reciprocal inhibition was demonstrated to increase with increasing postural demands (Lavoie et al. 1997, Kasai et al. 1998). However, it should be noted that the latter two studies measured the inhibitory influence of antagonistic activity upon the agonist without reference to the specific pathways that might have been involved. 'Reciprocal inhibition' in this broad sense comprises presynaptic inhibition and therefore has to be differentiated from 'disynaptic reciprocal inhibition' which describes a disynaptic circuit in the spinal cord. With this in mind, the results of Nielsen \& Kagamihara (1992) are not contradictory to the observations cited above (Nielsen \& Kagamihara 1993, Lavoie et al. 1997, Kasai et al. 1998) when they report diminished disynaptic reciprocal inhibition during unstable stance (standing on one leg, leaning backwards or standing on an unstable platform) compared to normal stance or sitting. Altogether, it is unlikely that reciprocal inhibition is the main driving force behind changes in the reflex excitability following balance training. Convincing support comes from training studies which have reported $\mathrm{H}$-reflex modulation without any changes in the background EMG activity and the level of co-contraction respectively (Trimble \& Koceja 1994,
Gruber et al. 2007b, Taube et al. 2007a,b). Thus, postsynaptic mechanisms are unlikely to be responsible for reflex alterations in these studies.

The observations cited in the preceding text point towards an important function of presynaptic mechanisms. Supraspinal centres are thought to control the amount of afferent input depending on the functional role of a respective target muscle by adjusting the amount of presynaptic inhibition. For example, Nielsen \& Kagamihara (1993) observed reduced presynaptic inhibition when the muscles surrounding the ankle joint were synchronously activated (co-contracted) during postural tasks. This reduction was however apparent $50 \mathrm{~ms}$ before the joint stabilizing co-contraction. The authors emphasized that the peripheral feedback cannot manifest itself before the onset of contraction. Based on this and the observation that presynaptic inhibition was independently controlled for the medial gastrocnemius compared with the tibialis anterior and soleus, Nielsen \&. Kagamihara (1993) supposed a central control of interneurones conveying the inhibition. With respect to balance training, it was assumed that supraspinalinduced presynaptic inhibition of la afferents is intensified by such an intervention (Gruber et al. $2007 \mathrm{~b}$, Taube et al. 2007a). This assumption is mainly based on the fact that $\mathrm{H}$-reflexes were solely reduced at the time of the perturbation induced LLR ( $120 \mathrm{~ms}$ ) whereas they remained unchanged at the SLR ( $\sim 50 \mathrm{~ms}$ ) (Taube et al. 2007a). A previous study showed that time constraints prevent supraspinal influence at the SLR but not at the LLR (Taube et al. 2006). As a consequence, supraspinal control of presynaptic inhibition fails to influence SLR and may not be modulated until the occurrence of the LLR.

\section{Supraspinal adaptations}

Apart from the spinal system, multiple supraspinal structures are essential to control upright posture in humans. The basal ganglia, the cerebellum and the brainstem have important functions in the organization of posture (for a review, see Visser \& Bloem 2005, Lalonde \& Strazielle 2007). Furthermore, recent applications of electrophysiological and imaging techniques indicated that the cerebral cortex contributes to balance control (for a review, see Jacobs \& Horak 2007). Due to the easier accessibility of cortical compared with subcortical structures, adaptations following balance training are best known for the motor cortex.

Techniques for measuring supraspinal adaptations. Noninvasive electrophysiological and brain imaging techniques have provided an insight into the supraspinal control of human posture. With these techniques it was possible to identify some of the cortical adaptations 
associated with balance training. The corticospinal excitability during postural tasks can be assessed by means of transcranial magnetic stimulation (TMS) (Lavoie et al. 1995). However, it must be noted that the rise time of the magnetically evoked 'motor evoked potential' (MEP) is long enough to allow several pathways to contribute to its facilitation. Thus, changes in the excitability of cortical, subcortical and/or spinal neurones might influence the size of the MEP (Maertens de Noordhout et al. 1992, Ugawa et al. 1995). Consequently, excitability changes assessed by TMS alone cannot be attributed to specific structures of the central nervous system (Nielsen \& Petersen 1995).

To counteract this limitation, several approaches have been undertaken. One method is to measure the corticospinal excitability by means of TMS and additionally apply electrical stimulation of the tibial nerve in order to assess the 'spinal excitability' (Solopova et al. 2003). Differential modulation of the MEP and H-reflex may point towards changes in the excitability of cortico motor neurones. A limitation of this technique however is that the H-reflex is not solely dependent on the excitability level of the motor neurone pool but is also influenced by presynaptic inhibition. Furthermore, comparison of MEP and H-reflex cannot exclude excitability changes on the interneurone level (Burke et al. 1984, Nielsen \& Petersen 1995). Apart from these limitations, responses after peripheral nerve stimulation might not always activate the same population of motor neurones and might be differently affected by changes of the motor neurone excitability than responses mediated via the corticospinal tract (Morita et al. 1999).

More reliable methods of inferring changes in the cortical excitability are conditioning of the $\mathrm{H}$-reflex by TMS (Nielsen et al. 1993b), the comparison of magnetically and electrically evoked MEPs (Hess et al. 1987) and paired focal TMS (Kujirai et al. 1993). For the H-reflex conditioning method, an H-reflex of constant size [based on the results of Crone et al. (1990), around $20 \%$ of $\mathrm{M}_{\max } \mathrm{l}$ is evoked almost simultaneously with an MEP so that both volleys coincide at the motor neuronal level. Depending on the time interval between TMS and peripheral nerve stimulation, activity in specific pathways of the corticospinal tract can be evaluated. The latency of the TMS volley arriving at the $x$-motor neurone is some milliseconds shorter than the latency of the peripheral volley. Accordingly, the earliest effect of the descending corticospinal pulse on the H-reflex can be found when the $\mathrm{H}$-reflex is released approximately $2-4 \mathrm{~ms}$ before the TMS. This earliest observable H-reflex facilitation can (at least within the first $0.5-1 \mathrm{~ms}$ after its onset) most likely be attributed to the influence of direct monosynaptic projections from the motor cortex synapsing to spinal motor neurones (Nielsen et al. 1993b, Petersen et al. 1998b). As these projections are considered to be free from presynaptic inhibition (Nielsen \& Petersen 1994, Jackson et al. 2006), changes in the conditioned $\mathrm{H}$-reflex are in all likelihood caused by alterations in the excitability of cortical interneurones and/or of the cortico motor neurones themselves (see Fig. 3).

Another method of assessing changes in the cortical excitability is the comparison of MEPs evoked by TMS and transcranial electrical stimulation (TES). Although both TMS and TES elicit descending corticospinal volleys, the mechanisms of activation differ. TMS depolarizes cortico motor neurones trans-synaptically and causes predominantly 'indirect' corticospinal volleys ('I-waves') (Di Lazzaro et al. 1998). On the other hand, TES activates the corticospinal neurones more directly at an axonal site, resulting in a so-called 'D-wave' (Di Lazzaro et al. 1999). The electrically evoked responses are therefore less strongly influenced by the excitability of the motor cortex than those to TMS.

Paired focal TMS can be applied to assess the amount of intracortical inhibition and intracortical facilitation. Depending on the interstimulus interval (ISI), the influence of a subthreshold stimulus on the response of a subsequent suprathreshold stimulus reveals the level of intracortical inhibition (ISIs between 1 and $5 \mathrm{~ms}$ ) or intracortical facilitation (ISIs between 8 and $15 \mathrm{~ms}$ ) (Kujirai et al. 1993). The latter method is easier to accomplish than $\mathrm{H}$-reflex conditioning or the combined application of TMS and TES. However, it is very susceptible to excitability changes within the motor neurone pool and is therefore difficult to use during dynamic contractions.

Neuroimaging techniques such as positron emission tomography (PET) allow the measuring of regional cerebral blood flow during the performance of different tasks (see Fig. 4). The advantage of PET compared to TMS is the greater accessibility of different brain areas (for example the cerebellum or the basal ganglia). However, the temporal resolution of this technique is not sufficiently high to detect changes during fast, and in particular, corrective movements. This temporal resolution is not defined by technological restrictions but rather limited by the velocity of the intracortical metabolic processes. Thus, it seems unlikely that technical development can resolve this problem in future.

Cortical contribution to the control of balance. Based on the early work of Sherrington (1910), it has commonly been accepted that the motor cortex has a minor role in controlling human posture. Instead, subcortical structures are considered essential to maintain equilibrium (Prentice \& Drew 2001). However, recent observations indicate an important role of the cortex in maintaining postural control in both animals 


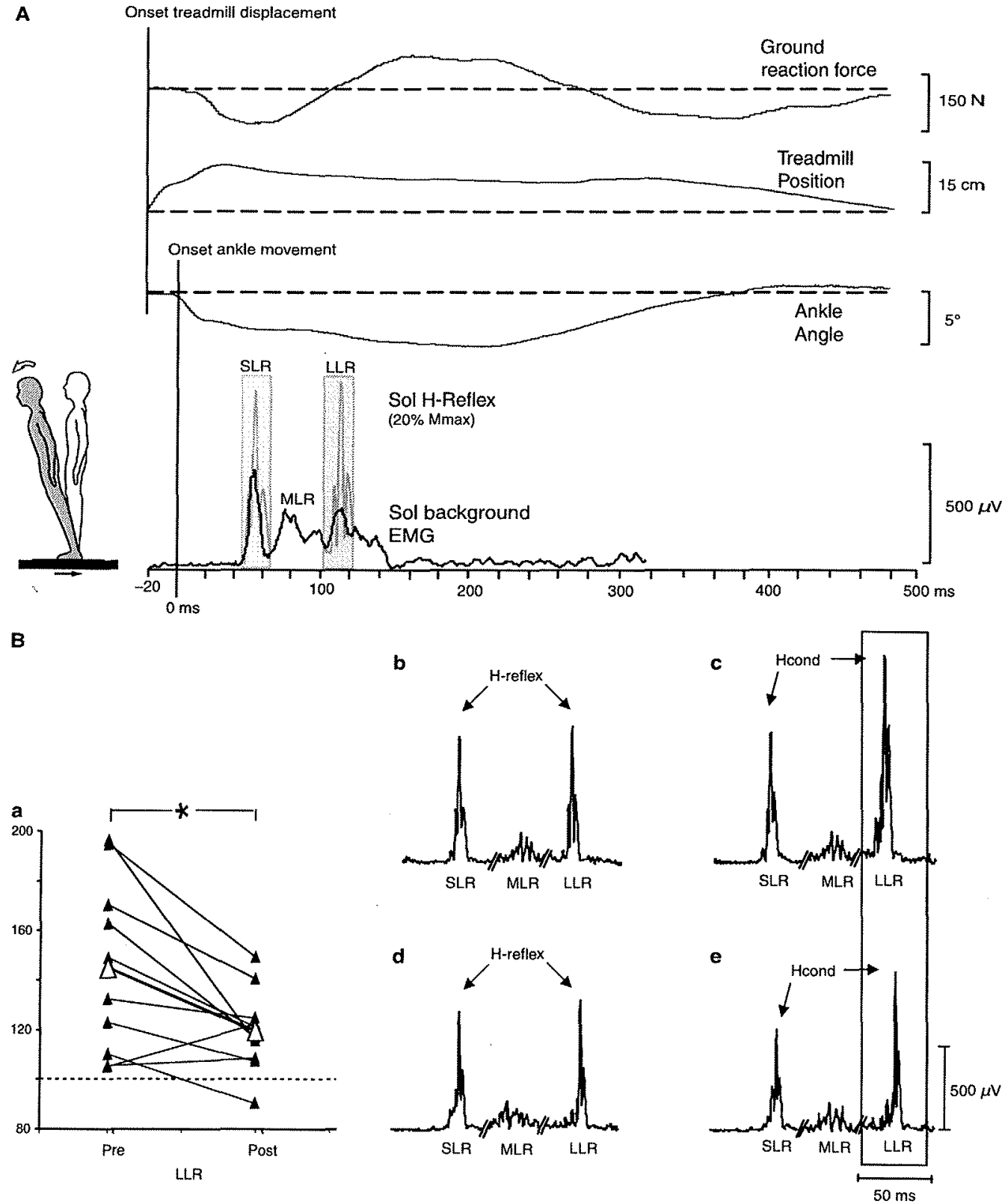

Figure 3 Training-induced changes in the contribution of direct corticospinal pathways during the compensation of postural disturbances. (A) Onset of the treadmill displacement with the corresponding vertical ground reaction force and the beginning of ankle movement during perturbed stance on the treadmill. Time zero corresponds to the onset of ankle movement. Soleus (SOL) background EMG (black line) of one subject is illustrated. SOL H-reflexes (grey lines) were timed to coincide with the peaks of SLR and LLR to create comparable motoneural activation at each stimulation point. (B) Effect of subthreshold transcranial magnetic stimulation (TMS) onto the H-reflexes (Hcond) at SLR and LLR before (b, c) and after balance training (d, e). This so-called H-reflex conditioning allows the evaluation of specific corticospinal pathways. (c, e) Influence of the fastest, direct corticospinal projections. Compared to the unconditioned H-reflexes (b, d), TMS solely facilitated the responses at the LLR (c, e). However, this facilitation was reduced after balance training indicating reduced excitability of direct corticospinal pathways (a; $\triangle$ group mean, $\mathbf{A}$ individual values; $P<0.05^{*}$ ) (modified from Taube et al. 2007a).

and humans. Direct electrophysiological recordings from cortico motor neurones in rabbits and cats demonstrated that the neural output from these cells was strongly related to the postural compensatory reaction, which took place in response to sinusoidal rotations of the support surface (Beloozerova et al. 
Figure 4 Changes in brain activation in two different standing positions. Illustrated are significant increases in the regional cerebral blood flow ( $\mathrm{rCBF}$ ) from standing upright to standing in a tandem position. Enhanced $\mathrm{rCBF}$ was observed in the anterior and posterior vermis and the midbrain corresponding to the red nucleus. The numeral denotes $z$-directional distance from the anterior-posterior commissural line on Talairach's standardized brain atlas. The coloured bat indicates $Z$-values from 0 to 5 (figure from Ouchi et al. 1999, with kind permission of Oxford University Press).

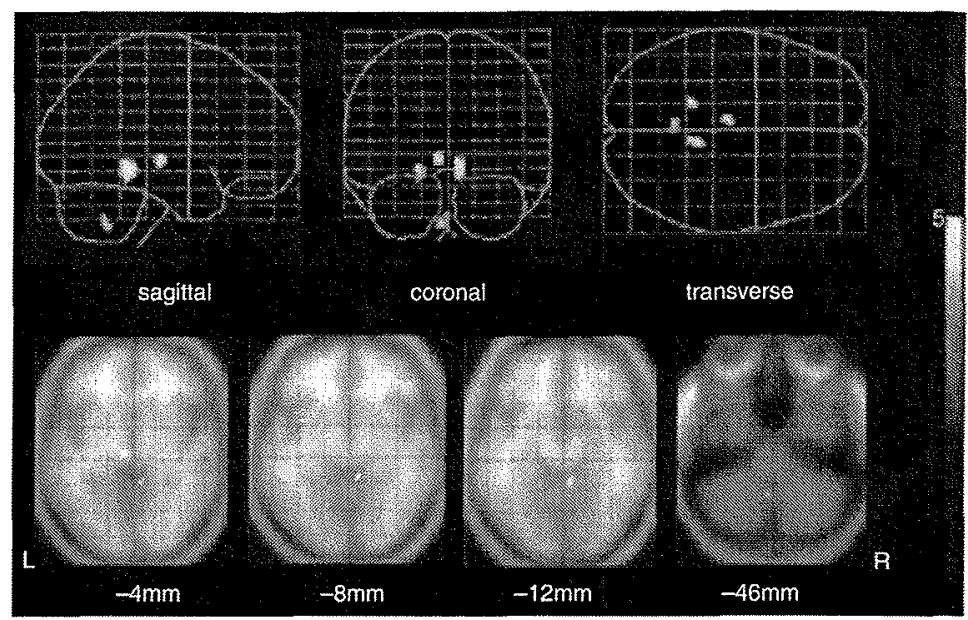

$2003,2005)$. In humans, noninvasive electrophysiological techniques like TMS, PET or electroencephalography also indicated that cortical control is involved in a variety of postural tasks (Ouchi et al. 1999, Jacobs \& Horak 2007, for a review). For example, during walking, the central nervous system is confronted to dynamically balance multiple body segments with a high centre of mass over a small base of support. Although this task is highly automated, it still relies on cortical input (for a review, see Nielsen 2003). The cortical influence is further increased when precise stepping is required or the gait pattern is disturbed (Schubert et al. 1999, Christensen et al. 2001).

Interestingly, phylogenetically newly developed structures contribute to the organization of walking. In primates and humans, a direct monosynaptic corticospinal pathway descending from the motor cortex to the spinal motor neurones has emerged. In monkeys, such corticomotoneural projections were shown to be important for the initiation and execution of voluntary dynamic contractions of the forelimb (Fetz et al. 1989, Lemon \& Mantel 1989). In humans, the direct pathways are thought to enable the great manual dexterity of the upper extremity (Porter \& Lemon 1993). However, when Nielsen et al. (1993b) conditioned the soleus H-reflex with TMS, they found that direct pathways in humans are also important for voluntary muscular activity of the leg. In this context, monosynaptic pathways were shown to contribute to the performance of gait (Petersen et al. 1998b). In a recent study, conditioning of the $\mathrm{H}$-reflex with subthreshold TMS indicated that direct corticospinal projections to the lower extremity are important for the neuromuscular control of perturbed stance (Taube et al. 2006). In contrast to walking, the initial compensatory response following rapid postural disturbances is organized at the spinal level as time constraints prevent influence of cortical and subcortical structures. The time of cortical involvement is then dependent on the minimum sum of afferent and efferent conduction time as well as on the time for central processing. For the soleus and the tibialis anterior, initial latencies for such a transcortical loop were assumed to be around 85-100 ms (Petersen et al. 1998a, Christensen et al. 2001, Taube et al. 2006).

The corticospinal excitability increases during unstable stance conditions (e.g. standing tiptoe, leaning forwards, standing on a free-swinging platform) (Lavoie et al. 1995, Solopova et al. 2003). Recent observations indicate that cortical excitability might also be altered during normal stance (unperturbed and with a stable support surface) (Soto et al. 2006). In the latter study, intracortical inhibition and intracortical facilitation were assessed during standing, sitting at rest and voluntary plantarflexion by means of paired focal TMS. During normal stance, intracortical inhibition of the soleus muscle was decreased compared with rest but did not differ with respect to voluntary tonic plantarflexion (Soto et al. 2006). Thus, the authors assumed a similar cortical involvement between standing and voluntary plantarflexion. However, they could not exclude that this effect was partially caused by changes in the spinal excitability. The observation of a differential modulation of MEPs evoked by TMS and TES during supported and natural stance further emphasize the role of the motor cortex in the standing position (Tokuno, Taube and Cresswell, unpublished results). Magnetically evoked MEPs increased from supported to natural stance whereas MEPs in response to TES did not change. As the electrically evoked responses are less strongly influenced by the excitability of the motor cortex than those to TMS, these results indicate an enhanced cortical excitability during natural standing. 
Cortical adaptations following balance training. Cortical plasticity in response to short- and long-term training was shown for both the upper and lower extremities (Pascual-Leone et al. 1995, Liepert et al. 1999, Perez et al. 2004, Jensen et al. 2005). However, it was assumed that adaptations resulting from balance training mainly took place at the spinal level due to the high intermuscular activation frequencies observed during stabilization tasks on an unstable platform (Gollhofer 2003). This assumption did not consider behavioural changes during balance training, which suggest that central modifications also play a role in learning and modifying postural responses (Horak \& Nashner 1986, Diener et al. 1988). For example, Horak et al. (1989) demonstrated that prior experience as well as knowledge about the magnitude of the postural disturbance affected the compensatory response. When subjects expected a larger perturbation than what actually took place, they over-responded. The opposite was true when a smaller perturbation was expected. Therefore, it was argued that both peripheral and central mechanisms modulate actual and anticipated perturbation characteristics. Roughly two decades later, improved balance performance was actually shown to be associated with cortical plasticity (Beck et al. 2007, Taube et al. 2007a, Schubert et al. 2008). Taube et al. (2007a) investigated cortical contribution to the LLR of the soleus muscle during perturbed stance before and after 4 weeks of balance training. H-reflexes, which were timed to coincide with the LLR around $120 \mathrm{~ms}$, were conditioned by subthreshold TMS. The time between electrical stimulation of the tibial nerve (H-reflex) and TMS (MEP) was chosen to reflect excitability in direct monosynaptic corticospinal projections. The facilitation of these direct pathways was reduced after balance training (Fig. 3). As these projections are considered to be free from presynaptic inhibition, this indicates reduced cortical excitability following postural training at the time of the LLR. These cortical adaptations were negatively correlated with changes in stance stability, i.e. subjects who reduced their cortical excitability to a greater extent showed greater improvements in stance stability. As there was no such correlation between changes in stance stability and changes in the $\mathrm{H}$-reflex, the improvement in balance performance was argued to rely mostly on supraspinal adaptations.

Task-specific supraspinal adaptation. Other studies have extended the observation of cortical plasticity following balance training by showing that this supraspinal plasticity was highly task specific (Beck et al. 2007, Schubert et al. 2008). In both studies, adaptations after balance training were compared with adaptations induced by ballistic strength training. Training effects were assessed at rest, during postural disturbance and during voluntary ankle movement. Beck et al. (2007) found that training effects were only apparent during the performance of the trained task: corticospinal excitability was reduced during compensatory reactions to translational disturbances in balancetrained subjects whereas MEP recruitment increased in the voluntary plantar-/dorsiflexion task after ballistic strength training. No changes were observed in the nontrained condition and at rest. These results indicate that not only spinal but also corticospinal adaptations are highly task specific. It therefore seems important that independent of the site of adaptation, the congruence of the (postural) task during training and electrophysiological assessment must be given in order to detect (balance) training-specific effects. This assumption is further strengthened by the results of Schubert et al. (2008), who assessed alterations in the excitability of direct corticospinal pathways by means of $\mathrm{H}$-reflex conditioning with TMS. Following balance training, cortical excitability was reduced during the execution of the postural task in accordance with the studies mentioned above. However, when balance-trained subjects were measured in the voluntary task, enhanced cortical excitability was evident. The improved explosive force production following balance training might therefore be caused by an enhanced cortical drive to the agonistic muscles. It can be speculated that (synaptic) efficiency of direct corticospinal projections to the muscles encompassing the ankle joint had been increased by balance training and could be utilized in the voluntary contraction. The question remains as to how the reduced corticospinal excitability following balance training during the execution of balance tasks can be explained.

Indication for subcortical plasticity. All studies focusing on supraspinal adaptations in response to balance training reported reduced corticospinal and cortical excitability when measuring during postural tasks. As the H-reflex amplitudes either remained the same (Beck et al. 2007, Schubert et al. 2008) or were reduced (Taube et al. 2007a) while the background EMG activity was unaltered, the authors assumed that subcortical mechanisms had become more relevant in the generation of muscular output. This assumption was based on previous skill acquisition studies using TMS and functional magnetic resonance imaging. These studies have shown that motor cortical activity was large during the initial training phase (i.e. during skill acquisition) but decreases with progressive training (i.e. automatization) (Pascual-Leone et al. 1994, Muellbacher et al. 2001, Floyer-Lea \& Matthews 2004, Puttemans et al. 2005, Doyon \& Benali 2005, for a review). Conversely, activity in subcortical regions like the basal ganglia and the cerebellum increased with 
(a)

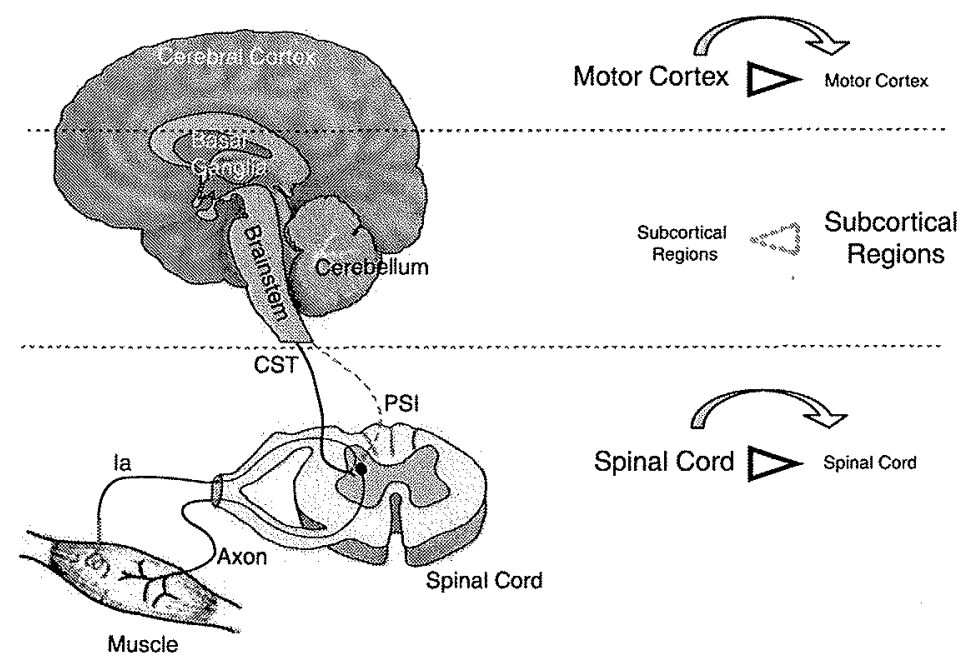

Figure 5 Simplified illustration of balance training-induced adaptations assessed during postural tasks. (a) Structures of the nervous system, which are considered to play an important role in the maintenance and recovery of balance. Sensory information from visual, vestibular, cutaneous and proprioceptive sources is integrated into postural control. With respect to the somatosensory system, changes in muscle length after perturbation are signalled by la and II (not illustrated) afferents originating from the muscle spindle. This information is transmitted to the spinal cord and to supraspinal centres (the latter connection is not displayed). The early part of the compensatory response (the short and the medium-latency response) is processed at the spinal level. After approximately $90-100 \mathrm{~ms}$ there is sufficient time for supraspinal sources to control muscular output (the LLR), e.g. via the corticospinal tract (CST) emanating from the motor cortex. (b) Neither the spinal nor the supraspinal structures generate stereotypical compensatory reactions after postural disturbances. Prior experience (e.g. balance training) or anticipation of the destabilizing stimulus as well as the context-specific intention can lead to changes in the postural response. Balance training is thought to reduce spinal reflex excitability by increasing the supraspinal-induced presynaptic inhibition (PSI). This reduction ( $\triangleright$ ) is schematically illustrated in the bottom line. Another well documented adaptation after balance training is the reduction in cortical involvement (first line). It is therefore assumed that training of balance skills and improved postural control after balance training strongly relies on subcortical structures [indicated as a grey dotted triangle (-) in the middle line].

increasing task automatization (Floyer-Lea \& Matthews 2004, Puttemans et al. 2005). The importance of subcortical structures for automatic (overlearned) motor tasks as well as for postural control was highlighted in several studies (for a review, see Doyon 1997). For example, activity in subcortical regions increased when the postural demands were enhanced, i.e. when a transition was made from a normal standing position into a tandem stance (Ouchi et al. 1999, Fig. 4).

Regarding the learning of postural strategies, it was shown that patients with cerebellar deficits showed inability to functionally adapt their long-latency reflex gain in response to changes in a perturbation task (Nashner 1976). Patients as well as healthy subjects demonstrated LLR at $120 \mathrm{~ms}$ following translational or rotational perturbations. Healthy subjects were able to avoid inappropriate compensatory responses following three to five trials, whereas the patients were either significantly slower or completely unable to adapt their responses. The importance of cerebellar structures for the acquisition of balance skills makes it reasonable to assume that balance training induces a 'shift in move- ment control' from cortical to more subcortical and cerebellar structures (Fig. 5). However, due to the difficulty in accessing of subcortical structures using current measuring techniques, there is no direct evidence as to how these structures adapt in response to balance training.

\section{Conclusions and prospects}

Balance training is beneficial for prevention and rehabilitation as well as for improving motor performance with respect to posture, strength and jumping. This is not only relevant for patients and elderly adults but also for athletes. The underlying neural adaptations were shown to occur at different sites of the central nervous system and the plasticity of the spinal, corticospinal and cortical pathways proved to be highly task specific. So far, little is known about the plasticity of cerebellar and subcortical areas with regard to balance training. The difficulty in accessing these structures during postural tasks might be overcome by advancing existing electrophysiological and imaging techniques. 


\section{Conflict of interest}

There are no conflicts of interest.

The authors are very grateful to Assoc. Prof. Andrew Cresswell and Dr Craig Tokuno of the School of Human Movement Studies, University of Queensland, Australia, for their kind revision of this article and their valuable advice.

\section{References}

Aagaard, P., Simonsen, E.B., Andersen, J.L., Magnusson, P. \& Dyhre-Poulsen, P. 2002. Neural adaptation to resistance training: changes in evoked $\mathrm{V}$-wave and $\mathrm{H}$-reflex responses. J Appl Physiol 92, 2309-2318.

Ashton-Miller, J.A., Wojtys, E.M., Huston, L.J. \& Fry-Welch, D. 2001. Can proprioception really be improved by exercises? Knee Surg Sports Traumatol Arthrosc 9, 128-136.

Bahr, R. \& Bahr, I.A. 1997. Incidence of acute volleyball injuries: a prospective cohort study of injury mechanisms and risk factors. Scand J Med Sci Sports 7, 166-171.

Banaschewski, T., Besmens, F., Zieger, H. \& Rothenberger, A. 2001. Evaluation of sensorimotor training in children with ADHD. Percept Mot Skills 92, 137-149.

Beck, S., Taube, W., Gruber, M., Amtage, F., Gollhofer, A. \& Schubert, M. 2007. Task-specific changes in motor evoked potentials of lower limb muscles after different training interventions. Brain Res 1179, 51-60.

Beloozerova, I.N., Sirota, M.G., Swadlow, H.A., Orlovsky, G.N., Popova, L.B. \& Deliagina, T.G. 2003. Activity of different classes of neurons of the motor cortex during postural corrections. J Neurosci 23, 7844-7853.

Beloozerova, I.N., Sirota, M.G., Orlovsky, G.N. \& Deliagina, T.G. 2005. Activity of pyramidal tract neurons in the cat during postural corrections. J Neurophysiol 93, 1831-1844.

Bernier, J.N. \& Perrin, D.H. 1998. Effect of coordination training on proprioception of the functionally unstable ankle. J Orthop Sports Phys Ther 27, 264-275.

Bove, M., Trompetto, C., Abbruzzese, G. \& Schieppati, M. 2006. The posture-related interaction between Ia-afferent and descending input on the spinal reflex excitability in humans. Neurosci Lett 397, 301-306.

Bruhn, S., Kullmann, N. \& Gollhofer, A. 2004. The effects of a sensorimotor training and a strength training on postural stabilisation, maximum isometric contraction and jump performance. Int J Sports Med 25, 56-60.

Bruhn, S., Kullmann, N. \& Gollhofer, A. 2006. Combinatory effects of high-intensity-strength training and sensorimotor training on muscle strength. Int J Sports Med 27, 401-406.

Burke, D., Gandevia, S.C. \& McKeon, B. 1984. Monosynaptic and oligosynaptic contributions to human ankle jerk and H-reflex. J Neurophysiol 52, 435-448.

Campbell, A.J., Borrie, M.J. \& Spears, G.F. 1989. Risk factors for falls in a community-based prospective study of people 70 years and older. J Gerontol 44, M112-M117.

Capaday, C. \& Stein, R.B. 1987. Difference in the amplitude of the human soleus $H$ reflex during walking and running. J Physiol 392, 513-522.

Caraffa, A., Cerulli, G., Projetti, M., Aisa, G. \& Rizzo, A. 1996. Prevention of anterior cruciate ligament injuries in soccer. A prospective controlled study of proprioceptive training. Knee Surg Sports Traumatol Arthrosc 4, 19-21.

Chalmers, G.R. \& Knutzen, K.M. 2002. Soleus H-reflex gain in healthy elderly and young adults when lying, standing, and balancing. J Gerontol A Biol Sci Med Sci 57, B321-B329.

Chong, R.K., Ambrose, A., Carzoli, J., Hardison, L. \& Jacobson, B. 2001. Source of improvement in balance control after a training program for ankle proprioception. Percept Mot Skills 92, 265-272.

Christensen, L.O., Andersen, J.B., Sinkjaer, T. \& Nielsen, J. 2001. Transcranial magnetic stimulation and stretch reflexes in the tibialis anterior muscle during human walking. J Physiol 531, 545-557.

Close, J., Ellis, M., Hooper, R., Glucksman, E., Jackson, S. \& Swift, C. 1999. Prevention of falls in the elderly trial (PROFET): a randomised controlled trial. Lancet 353, 93-97.

Crone, C., Hultborn, H., Mazieres, L., Morin, C., Nielsen, J. \& Pierrot-Deseilligny, E. 1990. Sensitivity of monosynaptic test reflexes to facilitation and inhibition as a function of the test reflex size: a study in man and the cat. Exp Brain Res 81, $35-45$.

Di Lazzaro, V., Restuccia, D., Oliviero, A., Profice, P., Ferrara, L., Insola, A., Mazzone, P., Tonali, P. \& Rothwell, J.C. 1998. Effects of voluntary contraction on descending volleys evoked by transcranial stimulation in conscious humans. J Physiol 508, 625-633.

Di Lazzaro, V., Oliviero, A., Profice, P., Insola, A., Mazzone, P., Tonali, P. \& Rothwell, J.C. 1999. Effects of voluntary contraction on descending volleys evoked by transcranial electrical stimulation over the motor cortex hand area in conscious humans. Exp Brain Res 124, 525-528.

Diener, H.C., Horak, F.B. \& Nashner, L.M. 1988. Influence of stimulus parameters on human postural responses. $J \mathrm{Neu}$ rophysiol 59, 1888-1905.

Dietz, V., Horstmann, G. \& Berger, W. 1988. Involvement of different receptors in the regulation of human posture. Neurosci Lett 94, 82-87.

Dietz, V., Trippel, M., Discher, M. \& Horstmann, G.A. 1991. Compensation of human stance perturbations: selection of the appropriate electromyographic pattern. Neurosci Lett 126, 71-74.

Dorfman, L.J. \& Bosley, T.M. 1979. Age-related changes in peripheral and central nerve conduction in man. Neurology $29,38-44$.

Doyon, J. 1997. Skill learning. Int Rev Neurobiol 41, 273-294.

Doyon, J. \& Benali, H. 2005. Reorganization and plasticity in the adult brain during learning of motor skills. Curr Opin Neurobiol 15, 161-167.

Earles, D.R., Koceja, D.M. \& Shively, C.W. 2000. Environmental changes in soleus $\mathrm{H}$-reflex excitability in young and elderly subjects. Int J Neurosci 105, 1-13.

Eils, E. \& Rosenbaum, D. 2001. A multi-station proprioceptive exercise program in patients with ankle instability. Med Sci Sports Exerc 33, 1991-1998.

Eisen, A., Entezari-Taher, M. \& Stewart, H. 1996. Cortical projections to spinal motoneurons: changes with aging and amyotrophic lateral sclerosis. Neurology 46, 1396-1404.

Emery, C.A., Rose, M.S., McAllister, J.R. \& Meeuwisse, W.H. 2007. A prevention strategy to reduce the incidence of injury 
in high school basketball: a cluster randomized controlled trial. Clin J Sport Med 17, 17-24.

Faulkner, J.A., Brooks, S.V. \& Zerba, E. 1990. Skeletal muscle weakness and fatigue in old age: underlying mechanisms. Annu Rev Gerontol Geriatr 10, 147-166.

Fetz, E.E., Cheney, P.D., Mewes, K. \& Palmer, S. 1989. Control of forelimb muscle activity by populations of corticomotoneuronal and rubromotoneuronal cells. Prog Brain Res 80, 437-449.

Floyer-Lea, A. \& Matthews, P.M. 2004. Changing brain networks for visuomotor control with increased movement automaticity. J Neurophysiol 92, 2405-2412.

Freeman, M.A., Dean, M.R. \& Hanham, I.W. 1965. The etiology and prevention of functional instability of the foot. $J$ Bone Joint Surg Br 47, 678-685.

Gauffin, H., Tropp, H. \& Odenrick, P. 1988. Effect of ankle disk training on postural control in patients with functional instability of the ankle joint. Int J Sports Med 9, 141-144.

Gollhofer, A. 2003. Proprioceptive training: considerations for strength and power production. In: P.V. Komi (ed.) Strength and Power in Sport, pp. 331-342. Blackwell, Oxford.

Granacher, U., Gollhofer, A. \& Strass, D. 2006. Training induced adaptations in characteristics of postural reflexes in elderly men. Gait Posture 24, 459-466.

Gruber, M. \& Gollhofer, A. 2004. Impact of sensorimotor training on the rate of force development and neural activation. Eur J Appl Physiol 92, 98-105.

Gruber, M., Gruber, S.B., Taube, W., Schubert, M., Beck, S.C. \& Gollhofer, A. 2007a. Differential effects of ballistic versus sensorimotor training on rate of force development and neural activation in humans. J Strength Cond Res 21, 274282.

Gruber, M., Taube, W., Gollhofer, A., Beck, S., Amtage, F. \& Schubert, M. 2007b. Training-specific adaptations of $\mathrm{H}$ - and stretch reflexes in human soleus muscle. J Mot Behav 39 , 68-78.

de Haart, M., Geurts, A.C., Huidekoper, S.C., Fasotti, L. \& van Limbeek, J. 2004. Recovery of standing balance in postacute stroke patients: a rehabilitation cohort study. Arch Phys Med Rehabil 85, 886-895.

Hayashi, R., Tokuda, T., Tako, K. \& Yanagisawa, N. 1997. Impaired modulation of tonic muscle activities and $\mathrm{H}$-reflexes in the soleus muscle during standing in patients with Parkinson's disease. J Neurol Sci 153, 61-67.

Heitkamp, H.C., Horstmann, T., Mayer, F., Weller, J. \& Dickhuth, H.H. 2001. Gain in strength and muscular balance after balance training. Int J Sports Med 22, 285-290.

Henriksson, M., Ledin, T. \& Good, L. 2001. Postural control after anterior cruciate ligament reconstruction and functional rehabilitation. Am J Sports Med 29, 359-366.

Herdman, S.J., Clendaniel, R.A., Mattox, D.E., Holliday, M.J. \& Niparko, J.K. 1995. Vestibular adaptation exercises and recovery: acute stage after acoustic neuroma resection. Otolaryngol Head Neck Surg 113, 77-87.

Hess, C.W., Mills, K.R. \& Murray, N.M. 1987. Responses in small hand muscles from magnetic stimulation of the human brain. J Physiol 388, 397-419.

Hirsch, M.A., Toole, T., Maitland, C.G. \& Rider, R.A. 2003. The effects of balance training and high-intensity resistance training on persons with idiopathic Parkinson's disease. Arch Phys Med Rehabil 84, 1109-1117.

Hoffman, M.A. \& Koceja, D.M. 1995. The effects of vision and task complexity on Hoffmann reflex gain. Brain Res 700, 303-307.

Holme, E., Magnusson, S.P., Becher, K., Bieler, T., Aagaard, P. \& Kjaer, M. 1999. The effect of supervised rehabilitation on strength, postural sway, position sense and re-injury risk after acute ankle ligament sprain. Scand J Med Sci Sports 9, 104-109.

Horak, F.B. \& Nashner, L.M. 1986. Central programming of postural movements: adaptation to altered support-surface configurations. J Neurophysiol 55, 1369-1381.

Horak, F.B., Diener, H.C. \& Nashner, L.M. 1989. Influence of central set on human postural responses. J Neurophysiol 62, 841-853.

Jackson, A., Baker, S.N. \& Fetz, E.E. 2006. Tests for presynaptic modulation of corticospinal terminals from peripheral afferents and pyramidal tract in the macaque.J Physiol 573, $107-120$.

Jacobs, J.V. \& Horak, F.B. 2007. Cortical control of postural responses. J Neural Transm 114, 1339-1348.

Jensen, J.L., Marstrand, P.C. \& Nielsen, J.B. 2005. Motor skill training and strength training are associated with different plastic changes in the central nervous system. $J$ Appl Physiol 99, 1558-1568.

Kasai, T., Kawanishi, M. \& Yahagi, S. 1998. Posture-dependent modulation of reciprocal inhibition upon initiation of ankle dorsiflexion in man. Brain Res 792, 159-163.

Katz, R., Meunier, S. \& Pierrot-Deseilligny, E. 1988. Changes in presynaptic inhibition of $\mathrm{Ia}$ fibres in man while standing. Brain 111, 417-437.

Kean, C.O., Behm, D.G. \& Young, W.B. 2006. Fixed foot balance training increases rectus femoris activation during landing and jump height in recreationally active women. J. Sports Sc. Med. 5, 138-148.

Koceja, D.M. \& Mynark, R.G. 2000. Comparison of heteronymous monosynaptic la facilitation in young and elderly subjects in supine and standing positions. Int J Neurosci 103, $1-17$.

Koceja, D.M., Markus, C.A. \& Trimble, M.H. 1995. Postural modulation of the soleus $\mathrm{H}$ reflex in young and old subjects. Electroencephalogr Clin Neurophysiol 97, 387-393.

Kujirai, T., Caramia, M.D., Rothwell, J.C., Day, B.L., Thompson, P.D., Ferbert, A., Wroe, S., Asselman, P. \& Marsden, C.D. 1993. Corticocortical inhibition in human motor cortex. J Physiol 471, 501-519.

Lagerquist, O., Zehr, E.P. \& Docherty, D. 2006. Increased spinal reflex excitability is not associated with neural plasticity underlying the cross-education effect. J Appl Physiol 100, 83-90.

Lalonde, R. \& Strazielle, C. 2007. Brain regions and genes affecting postural control. Prog Neurobiol 81, 45-60.

Lavoie, B.A., Cody, F.W. \& Capaday, C. 1995. Cortical control of human soleus muscle during volitional and postural activities studied using focal magnetic stimulation. Exp Brain Res 103, 97-107.

Lavoie, B.A., Devanne, H. \& Capaday, C. 1997. Differential control of reciprocal inhibition during walking versus 
postural and voluntary motor tasks in humans. I Neurophysiol 78, 429-438.

Lemon, R.N. \& Mantel, G.W.H. 1989. The influence of changes in discharge frequency of corticospinal neurones on hand muscles in the monkey. $J$ Physiol 413, 351-378.

Liepert, J., Terborg, C. \& Weiller, C. 1999. Motor plasticity induced by synchronized thumb and foot movements. Exp Brain Res 125, 435-439.

Liu-Ambrose, T., Khan, K.M., Eng, J.J., Janssen, P.A., Lord, S.R. \& McKay, H.A. 2004. Resistance and agility training reduce fall risk in women aged 75 to 85 with low bone mass: a 6-month randomized, controlled trial. I Am Geriatr Soc $52,657-665$.

Llewellyn, M., Yang, J.F. \& Prochazka, A. 1990. Human H-reflexes are smaller in difficult beam walking than in normal treadmill walking. Exp Brain Res 83, 22-28.

Lord, S.R., Clark, R.D. \& Webster, I.W. 1991. Physiological factors associated with falls in an elderly population. $J \mathrm{Am}$ Geriatr Soc 39, 1194-1200.

Maertens de Noordhout, A., Pepin, J.L., Gerard, P. \& Delwaide, P.J. 1992. Facilitation of responses to motor cortex stimulation: effects of isometric voluntary contraction. Ann Neurol 32, 365-370.

Maurer, C., Mergner, T. \& Peterka, R.J. 2006. Multisensory control of human upright stance. Exp Brain Res 171, 231250.

McGuine, T.A. \& Keene, J.S. 2006. The effect of a balance training program on the risk of ankle sprains in high school athletes. Am J Sports Med 34, 1103-1111.

Morita, H., Baumgarten, J., Petersen, N., Christensen, L.O. \& Nielsen, J. 1999. Recruitment of extensor-carpi-radialis motor units by transcranial magnetic stimulation and radialnerve stimulation in human subjects. Exp Brain Res 128, $557-562$.

Muellbacher, W., Ziemann, U., Boroojerdi, B., Cohen, L. \& Hallett, M. 2001. Role of the human motor cortex in rapid motor learning. Exp Brain Res 136, 431-438.

Myer, G.D., Ford, K.R., Brent, J.L. \& Hewett, T.E. 2006. The effects of plyometric vs. dynamic stabilization and balance training on power, balance, and landing force in female athletes. J Strength Cond Res 20, 345-353.

Myklebust, G., Engebretsen, L., Braekken, I.H., Skjolberg, A., Olsen, O.E. \& Bahr, R. 2003. Prevention of anterior cruciate ligament injuries in female team handball players: a prospective intervention study over three seasons. Clin J Sport Med 13, 71-78.

Myklebust, G., Engebretsen, L., Braekken, I.H., Skjolberg, A., Olsen, O.E. \& Bahr, R. 2007. Prevention of noncontact anterior cruciate ligament injuries in elite and adolescent female team handball athletes. Instr Course Lect 56, 407418.

Mynark, R.G. \& Koceja, D.M. 1997. Comparison of soleus H-reflex gain from prone to standing in dancers and controls. Electroencephalogr Clin Neurophysiol 105, 135-140.

Mynark, R.G. \& Koceja, D.M. 2002. Down training of the elderly soleus $\mathrm{H}$ reflex with the use of a spinally induced balance perturbation. J Appl Physiol 93, 127-133.

Mynark, R.G., Koceja, D.M. \& Lewis, C.A. 1997. Heteronymous monosynaptic la facilitation from supine to standing and its relationship to the soleus H-reflex. Int J Neurosci 92 171-186.

Nashner, L.M. 1976. Adapting reflexes controlling the human posture. Exp Brain Res 26, 59-72.

Nelson, M.E., Layne, J.E., Bernstein, M.J., Nuernberger, A., Castaneda, C., Kaliton, D., Hausdorff, J., Judge, J.O., Buchner, D.M., Roubenoff, R. \& Fiatarone Singh, M.A. 2004. The effects of multidimensional home-based exercise on functional performance in elderly people. $J$ Gerontol A Biol Sci Med Sci 59, 154-160.

Nielsen, J.B. 2003. How we walk: central control of muscle activity during human walking. Neuroscientist 9, 195-204.

Nielsen, J. \& Kagamihara, Y. 1992. The regulation of disynaptic reciprocal la inhibition during co-contraction of antagonistic muscles in man. J Physiol 456, 373-391.

Nielsen, J. \& Kagamihara, Y. 1993. The regulation of presynaptic inhibition during co-contraction of antagonistic muscles in man. J Physiol 464, 575-593.

Nielsen, J. \& Petersen, N. 1994. Is presynaptic inhibition distributed to corticospinal fibres in man? / Pbysiol 477, 47-58.

Nielsen, J. \& Petersen, N. 1995. Evidence favouring different descending pathways to soleus motoneurones activated by magnetic brain stimulation in man. J Physiol 486, 779-788.

Nielsen, J., Crone, C. \& Hultborn, H. 1993a. H-reflexes are smaller in dancers from The Royal Danish Ballet than in well-trained athletes. Eur J Appl Physiol Occup Physiol 66, 116-121.

Nielsen, J., Petersen, N., Deuschl, G. \& Ballegaard, M. 1993 b. Task-related changes in the effect of magnetic brain stimulation on spinal neurones in man. J Physiol 471, 223-243.

Ouchi, Y., Okada, H., Yoshikawa, E., Nobezawa, S. \& Futatsubashi, M. 1999. Brain activation during maintenance of standing postures in humans. Brain 122, 329-338.

Pascual-Leone, A., Grafman, J. \& Hallett, M. 1994. Modulation of cortical motor output maps during development of implicit and explicit knowledge. Science 263, 1287-1289.

Pascual-Leone, A., Nguyet, D., Cohen, L.G., Brasil-Neto, J.P., Cammarota, A. \& Hallett, M. 1995. Modulation of muscle responses evoked by transcranial magnetic stimulation during the acquisition of new fine motor skills. J Neurophysiol 74, $1037-1045$.

Paterno, M.V., Myer, G.D., Ford, K.R. \& Hewett, T.E. 2004. Neuromuscular training improves single-limb stability in young female athletes. I Orthop Sports Phys Ther 34, 305-316

Perez, M.A., Lungholt, B.K., Nyborg, K. \& Nielsen, J.B. 2004. Motor skill training induces changes in the excitability of the leg cortical area in healthy humans. Exp Brain Res 159, 197-205.

Petersen, N., Christensen, L.O., Morita, H., Sinkjaer, T. \& Nielsen, J. 1998a. Evidence that a transcortical pathway contributes to stretch reflexes in the tibialis anterior muscle in man. I Physiol 512, 267-276.

Petersen, N., Christensen, L.O.D. \& Nielsen, J.B. 1998b. The effect of transcranial magnetic stimulation on the soleus $\mathrm{H}$ reflex during human walking. $J$ Physiol 513, 599-610.

Petersen, W., Braun, C., Bock, W., Schmidt, K., Weimann, A., Drescher, W., Eiling, E., Stange, R., Fuchs, T., Hedderich, J. 
\& Zantop, T. 2005. A controlled prospective case control study of a prevention training program in female team handball players: the German experience. Arch Orthop Trauma Surg 125, 614-621.

Porter, R. \& Lemon, R.N. 1993. Corticospinal Function and Voluntary Movement. Monographs of the Physiological Society, No. 45. Oxford University Press, New York.

Prentice, S.D. \& Drew, T. 2001. Contributions of the reticulospinal system to the postural adjustments occurring during voluntary gait modifications. J Neuropbysiol 85, 679-698.

Puttemans, V., Wenderoth, N. \& Swinnen, S.P. 2005. Changes in brain activation during the acquisition of a multifrequency bimanual coordination task: from the cognitive stage to advanced levels of automaticity. $J$ Neurosci 25, 4270-4278.

Rine, R.M., Braswell, J., Fisher, D., Joyce, K., Kalar, K. \& Shaffer, M. 2004. Improvement of motor development and postural control following intervention in children with sensorineural hearing loss and vestibular impairment. Int J Pediatr Otorhinolaryngol 68, 1141-1148.

Robertson, M.C., Campbell, A.J., Gardner, M.M. \& Devlin, N. 2002. Preventing injuries in older people by preventing falls: a meta-analysis of individual-level data. $J$ Am Geriatr Soc 50, 905-911.

Rogers, M.W., Johnson, M.E., Martinez, K.M., Mille, M.L. \& Hedman, L.D. 2003. Step training improves the speed of voluntary step initiation in aging. J Gerontol A Biol Sci Med Sci 58, 46-51.

Rozzi, S.L., Lephart, S.M., Sterner, R. \& Kuligowski, L. 1999. Balance training for persons with functionally unstable ankles. J Orthop Sports Phys Ther 29, 478-486.

Schieppati, M. 1987. The Hoffmann reflex: a means of assessing spinal reflex excitability and its descending control in man. Prog Neurobiol 28, 345-376.

Schubert, M., Curt, A., Colombo, G., Berger, W. \& Dietz, V. 1999. Voluntary control of human gait: conditioning of magnetically evoked motor responses in a precision stepping task. Exp Brain Res 126, 583-588.

Schubert, M., Beck, S., Taube, W., Amtage, F., Faist, M. \& Gruber, M. 2008. Balance training and ballistic strength training are associated with task-specific cortico-spinal adaptations. Eur J Neurosci (in press).

Shaffer, S.W. \& Harrison, A.L. 2007. Aging of the somatosensory system: a translational perspective. Phys Ther 87 , 193-207.

Sherrington, C.S. 1910. Flexion-reflex of the limb, crossed extension-reflex, and reflex stepping and standing. J Pbysiol 40, 28-121.

Skinner, H.B., Barrack, R.L. \& Cook, S.D. 1984. Age-related decline in proprioception. Clin Orthop Relat Res 184, 208211.

Solopova, I.A., Kazennikov, O.V., Deniskina, N.B., Levik, Y.S. \& Ivanenko, Y.P. 2003. Postural instability enhances motor responses to transcranial magnetic stimulation in humans. Neurosci Lett 337, 25-28.

Soto, O., Valls-Sole, J., Shanahan, P. \& Rothwell, J. 2006. Reduction of intracortical inhibition in soleus muscle during postural activity. J Neurophysiol 96, 1711-1717.
Taube, W., Schubert, M., Gruber, M., Beck, S., Faist, M. \& Gollhofer, A. 2006. Direct corticospinal pathways contribute to neuromuscular control of perturbed stance. $J A p p l$ Physiol 101, 420-429.

Taube, W., Gruber, M., Beck, S., Faist, M., Gollhofer, A. \& Schubert, M. 2007a. Cortical and spinal adaptations induced by balance training: correlation between stance stability and corticospinal activation. Acta Physiol (Oxf) 189, 347-358.

Taube, W., Kullmann, N., Leukel, C., Kurz, O., Amtage, F. \& Gollhofer, A. 2007b. Differential reflex adaptations following sensorimotor and strength training in young elite athletes. Int J Sports Med 28, 999-1005.

Tokuda, T., Tako, K., Hayashi, R. \& Yanagisawa, N. 1991. Disturbed modulation of the stretch reflex gain during standing in cerebellar ataxia. Electroencephalogr Clin Neurophysiol 81, 421-426.

Tokuno, C.D., Carpenter, M.G., Thorstensson, A., Garland, S.J. \& Cresswell, A.G. 2007. Control of the triceps surae during the postural sway of quiet standing. Acta Physiol (Oxf) 191, 229-236.

Trimble, M.H. 1998. Postural modulation of the segmental reflex: effect of body tilt and postural sway. Int J Neurosci 95, 85-100.

Trimble, M.H. \& Koceja, D.M. 1994. Modulation of the triceps surae H-reflex with training. Int J Neurosci 76, 293303.

Trimble, M.H. \& Koceja, D.M. 2001. Effect of a reduced base of support in standing and balance training on the soleus H-reflex. Int J Neurosci 106, 1-20.

Tsuruike, M., Koceja, D.M., Yabe, K. \& Shima, N. 2003. Age comparison of H-reflex modulation with the Jendrassik maneuver and postural complexity. Clin Neurophysiol 114, 945-953.

Ugawa, Y., Terao, Y., Hanajima, R., Sakai, K. \& Kanazawa, I. 1995. Facilitatory effect of tonic voluntary contraction on responses to motor cortex stimulation. Electroencephalogr Clin Neurophysiol 97, 451-454.

Verhagen, E., van der Beek, A., Twisk, J., Bouter, L., Bahr, R. \& Van Mechelen, W. 2004. The effect of a proprioceptive balance board training program for the prevention of ankle sprains: a prospective controlled trial. Am I Sports Med 32, 1385-1393.

Visser, J.E. \& Bloem, B.R. 2005. Role of the basal ganglia in balance control. Neural Plast 12, 161-174.

Voigt, M., Chelli, F. \& Frigo, C. 1998. Changes in the excitability of soleus muscle short latency stretch reflexés during human hopping after 4 weeks of hopping training. Eur J Appl Physiol Occup Physiol 78, $522-532$.

Wedderkopp, N., Kaltoft, M., Lundgaard, B., Rosendahl, M. \& Froberg, K. 1999. Prevention of injuries in young female players in European team handball. A prospective intervention study. Scand J Med Sci Sports 9, 41-47.

Wedderkopp, N., Kaltoft, M., Holm, R. \& Froberg, K. 2003. Comparison of two intervention programmes in young female players in European handball - with and without ankle disc. Scand J Med Sci Sports 13, 371375 . 
Whanger, A.D. \& Wang, H.S. 1974. Clinical correlates of the vibratory sense in elderly psychiatric patients. J Gerontol 29, $39-45$.

Wolfson, L., Judge, J., Whipple, R. \& King, M. 1995. Strength is a major factor in balance, gait, and the occurrence of falls. $J$ Gerontol A Biol Sci Med Sci 50, 64-67.

Wolpaw, J.R. \& Tennissen, A.M. 2001. Activity-dependent spinal cord plasticity in health and disease. Annu Rev Neurosci 24, 807-843.

Wulker, N. \& Rudert, M. 1999. Lateral ankle ligament rupture. When is surgical management indicated and when conservative therapy preferred? Orthopade 28, 476482.

Yaggie, J.A. \& Campbell, B.M. 2006. Effects of balance training on selected skills. J Strength Cond Res 20, 422428.

Yavuzer, G., Eser, F., Karakus, D., Karaoglan, B. \& Stam, H.J. 2006. The effects of balance training on gait late after stroke: a randomized controlled trial. Clin Rehabil 20, 960969.

Zehr, E.P. 2002. Considerations for use of the Hoffmann reflex in exercise studies. Eur J Appl Physiol 86, 455-468. 